University of Wollongong

Research Online

Faculty of Engineering - Papers (Archive)

Faculty of Engineering and Information

Sciences

$1-1-2005$

\title{
Towards real-time landslide risk management in an urban area
}

P. Flentje

University of Wollongong, pflentje@uow.edu.au

R. N. Chowdhury

University of Wollongong, robin@uow.edu.au

P. Tobin

Wollongong City Council

V. Brizga

Roads and Traffic Authority, Australia

Follow this and additional works at: https://ro.uow.edu.au/engpapers

Part of the Engineering Commons

https://ro.uow.edu.au/engpapers/388

\section{Recommended Citation}

Flentje, P.; Chowdhury, R. N.; Tobin, P.; and Brizga, V.: Towards real-time landslide risk management in an urban area 2005.

https://ro.uow.edu.au/engpapers/388

Research Online is the open access institutional repository for the University of Wollongong. For further information contact the UOW Library: research-pubs@uow.edu.au 


\title{
Towards real-time landslide risk management in an urban area
}

\author{
P.N.Flentje ${ }^{1} \&$ R.N.Chowdhury ${ }^{2}$ \\ Research Fellow ${ }^{1}$ and Emeritus Professor ${ }^{2}$, Faculty of Engineering, University of Wollongong, Wollongong, \\ NSW, Australia 2500 \\ P.Tobin \\ Geotechnical Engineer, Wollongong City Council, Wollongong, NSW, Australia
}

V.Brizga

Geotechnical Scientist, Roads and Traffic Authority of New South Wales, Wollongong, NSW, Australia

\begin{abstract}
With an average annual rainfall in the range $1200 \mathrm{~mm}-1800 \mathrm{~mm}$, landslides in Wollongong are triggered by periods of prolonged heavy rainfall. During such events, real-time pore water pressure, slope movement and rainfall data can be extremely useful for risk assessment and emergency management. A network of continuously monitored real-time landslide field stations has been established in Wollongong. This network will facilitate risk management operations, enhance our understanding of landslide triggering mechanisms and improve quantitative assessment of landslide hazard. Four stations have been established and additional stations are proposed. Data collection and management is fully automated yet manually accessible as required. The major benefit of this system is the accessibility and availability of fully automated graphical output via the web immediately as the data is received from the field stations. The widespread accessibility of this information in near real-time has clear benefits for risk management and emergency response decisions.
\end{abstract}

\section{INTRODUCTION}

This paper is primarily concerned with the management of landslide hazard and risk with the aid of a network of real-time continuously monitored webenabled landslide field stations. The importance of an observational approach is implicit in this strategy. Four such stations are currently operating in Wollongong, in the state of New South Wales, Australia. A wider network of field stations is proposed for the study area and extending to other landslide sites outside of the study area. The key features of these field stations are outlined here and some data from three of the stations are presented and discussed. Utilising the data from such stations requires the development of multi-agent strategies to facilitate the efficient dissemination of information and response. These implementations of the observational approach are one component of a comprehensive strategy for the management of landslide hazard and risk employed within the Wollongong area.

\subsection{The Wollongong Area}

The city of Wollongong is nestled on a narrow coastal plain approximately $70 \mathrm{~km}$ south of Sydney in the state of New South Wales (NSW), Australia as shown in Figure 1. Over the last 150 years of set- tlement the population of the Wollongong area has increased to about 200,000 people. The coastal plain is triangular in shape with a coastal length of $45 \mathrm{~km}$. The coastal plain is up to $17 \mathrm{~km}$ wide in the south and narrows sharply towards the north, disappearing north of Thirroul. The coastal plain is bounded to the north, west and south by an erosional escarpment ranging in height from $300 \mathrm{~m}$ up to $500 \mathrm{~m}$

The escarpment consists of slopes with moderate to steep inclinations with several intermediate benches and cliff lines. Spectacular cliffs of Hawkesbury Sandstone (of Middle Triassic age) cap the escarpment and there is dense vegetation over most of the escarpment below these cliffs.

The main road link to Sydney is the F6 Freeway that traverses the escarpment via Mount Ousley Road. There are several other road links from the coastal plain to the top of the escarpment such as at Bulli Pass (refer Figure 1). Lawrence Hargrave Drive links the northern suburbs to the F6 freeway via the spectacular near vertical $200 \mathrm{~m}$ high cliffs near Clifton, although one section of this road is currently closed due to landsliding (Hendrickx, et al., 2005 in prep).

The South Coast and the Unanderra to Mossvale railway lines also traverse the escarpment slopes and coastal plain and both provide important freight and 


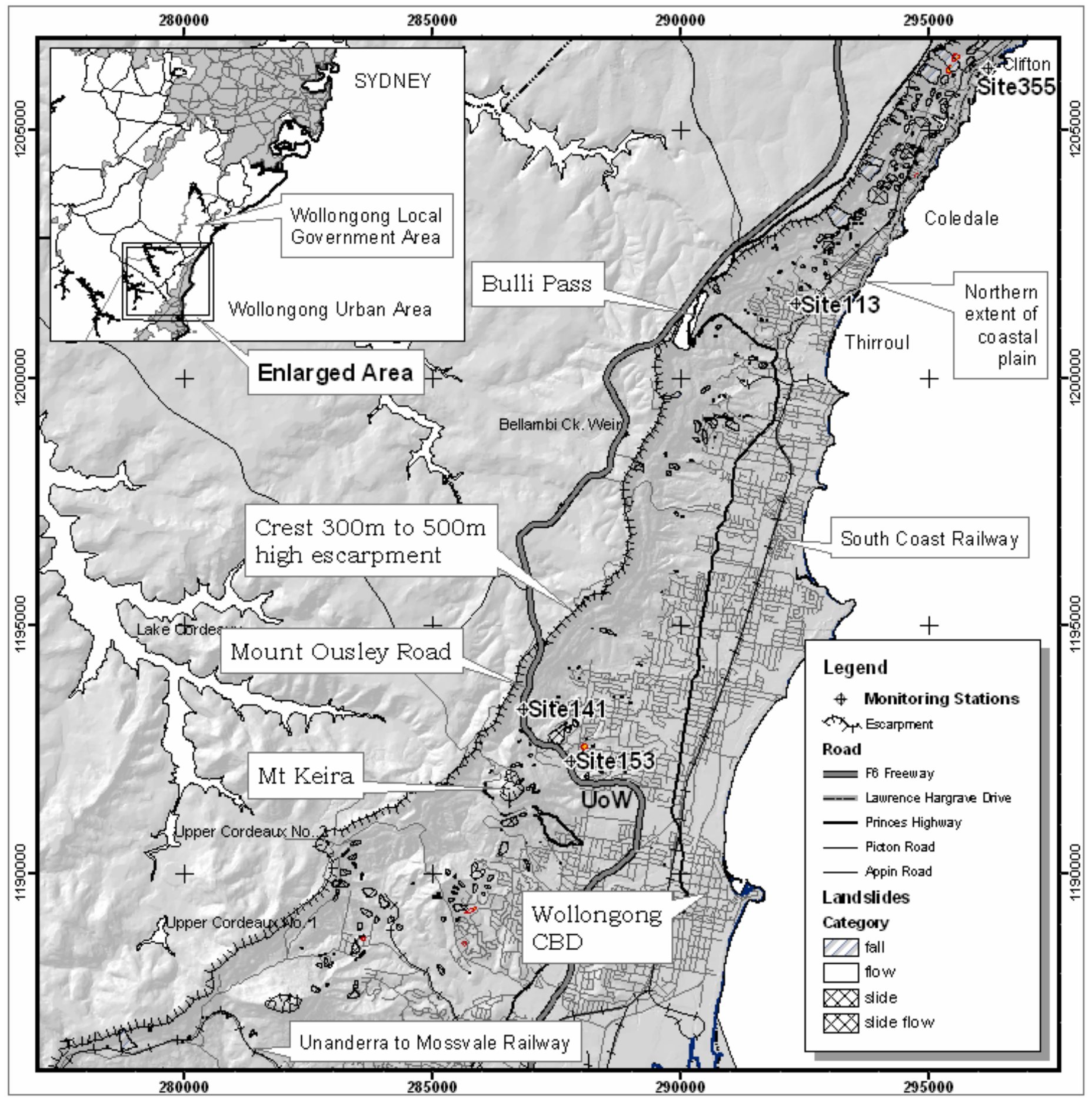

Figure 1. Location plan for the City of Wollongong showing the four field stations discussed in this paper.

passenger services between Sydney, Wollongong and the surrounding areas.

Processes and mechanisms of slope failure are controlled in Wollongong by factors such as stratigraphy and geotechnical strength parameters, hydrogeology, geomorphology, slope inclination and pore water pressure. Prolonged and/or intense rainfall is typically the trigger for significant landsliding. The average annual rainfall for Wollongong varies from $1200 \mathrm{~mm}$ on the coastal plain near the city centre up to $1800 \mathrm{~m}$ along the top of the escarpment.

\subsection{Background}

The landslide research team at the University of Wollongong (UoW) has carried out systematic research over the last twelve years with funding from the Australian Research Council (ARC) as well as significant support from several external industry partners. These include the Wollongong City Council (WCC), the Rail Corporation (RC), Geoscience Australia (GA) and, more recently, the Roads and Traffic Authority (RTA). During this research a number of aspects have been covered including the following: 
1 The development of a comprehensive GISbased datasets including boreholes and structural geology

2 The development of a comprehensive landslide inventory containing 570 landslide sites (Flentje, 1998, Chowdhury and Flentje 2002)

3 The development of comprehensive GIS-based maps of geology and landslides

4 Geological and geotechnical modelling, deterministic and probabilistic studies

5 GIS-based and numerical modelling of the spatial variability and recurrence of rainfall

6 Development of a strategic framework for assessment of landslide hazard and risk including qualitative and quantitative methods and including scope for both site-specific and area-specific studies (Ko Ko, 2001, Ko Ko et al 2004).

7 Knowledge-based modelling, using 'data mining' techniques, facilitating the preparation of GIS-based susceptibility maps for specific landslide types for a whole region (Chowdhury, R., et al., 2002).

\section{ESTABLISHING A REAL-TIME MONITORING STATION}

Equipment used to monitor a landslide in real-time currently starts at approximately $\$ 18,000$ AUS in 2004 and this does not include installation costs. This is clearly an inexpensive means of monitoring any landslide which poses a significant or moderate risk to infrastructure and especially if there is a moderate or even low risk to human safety. At present, four remotely accessible continuous monitoring stations have been built in Wollongong and selected data obtained from three of these stations are discussed in this paper.

The instruments used in the Wollongong applications include In-Place-Inclinometers (IPI's) and vibrating wire piezometers (vwp) installed at depth in boreholes. Rainfall Pluviometers have been installed at all the field stations to record rainfall as it occurs $(0.2 \mathrm{~mm}$ or $0.5 \mathrm{~mm}$ bucket tips).

The stations are all powered by small solar panels which charge 12 Volt 7.0 Ah sealed lead-acid batteries housed in Campbell Scientific PS/12 Power Supply/regulator units. Telecommunications are performed by Wavecom WMOD2 digital cellular mobile phones. Datalogging and on-site data management is carried out with Campbell Scientific CR10X data loggers. Slope Indicator has bundled these systems together and supplied them to the University of Wollongong together with the programming for the CR10X data loggers. Slope Indicator staff have completed the CR10X programming incorporating our research-based landslide triggering rainfall thresholds and other troubleshooting as required.
A discussion concerning the installation of inclinometer casing and vibrating wire piezometers is beyond the scope of this paper. However, it is worth noting that the IPI instrument itself is approximately $44 \mathrm{~cm}$ from wheel to wheel centre and approximately $38.2 \mathrm{~mm}$ in diameter. These dimensions highlight two important points. Firstly, the length can be extended by the addition of stainless steel tubing to whatever gauge length movement is to be monitored over. In one instance during local trials a 3m-gauge length was used, as the precise depth interval of shearing was not known. As landslide shearing progressed over a $1 \mathrm{~m}$ depth interval within this $3 \mathrm{~m}$ interval, inaccurate $\mathrm{A}$ axis values were recorded as the stainless steel gauge tubing flexed within what has turned out to be a poorly backfilled inclinometer casing which also flexed in undesirable (upslope) orientations, as discussed below. Clearly, as the depth and style of shearing is confirmed, the inclinometer gauge length should be reduced to an appropriate minimum length. Secondly, the $38.2 \mathrm{~mm}$ diameter occupies more than half of the typical $70 \mathrm{~mm}$ OD casing (approximately $58.5 \mathrm{~mm} \mathrm{ID)} \mathrm{restricting} \mathrm{the} \mathrm{amount} \mathrm{of}$ displacement that can occur with the instruments remaining accessible and serviceable from the ground surface. Wider diameter $85 \mathrm{~mm}$ OD casing $(73 \mathrm{~mm}$ ID) inclinometer casing allows greater movement before serviceability issues will be encountered.

\subsection{Real-time data acquisition and data management}

Data management in real-time is an integral aspect of this monitoring and the key component of the University of Wollongong system. The LoggerNet and MultiMon software from Campbell Scientific and Slope Indicator respectively enable remote access to the field stations from an office based PC with a modem and a telephone connection.

The programmable CR10X data logger is the intelligent component of each field station. The data loggers are setup to record data hourly and in low rainfall/dry times download data to the office weekly. When rainfall intensity increases the frequency of data download is increased to daily and even up to 4 hourly (at which time the datalogger also starts recording data at 5 minute intervals). The rainfall intensity thresholds to trigger the varied data logger responses are coded in the software over antecedent intervals spanning 6 hours up to 120 days.

The office based PC can contact the field stations at any time and download data. Alarm conditions can be set on the office PC software whereby colour coded data boxes on the graphical displays change colour as thresholds are reached and or exceeded. 
The real challenge is then to disseminate this data to geotechnical colleagues and other managers in a timely fashion. This innovative aspect of the strategy adopted by the landslide research team is discussed in Section 7 below.

\section{DATA FROM REAL-TIME MONITORING STATION INSTALLED AT SITE 113}

Site 113 is a $3 \mathrm{~m}$ deep slide category landslide having a volume of approximately $25,000 \mathrm{~m}^{3}$ that was selected as the first trial research site for several reasons as summarised below:

1 It is an active shallow slide category landslide that has destroyed 5 houses and 1 school building during the last 50 years

2 It has been reactivated 14 times over a period of 50 years (highest known frequency of 570 landslides in study area) and was therefore likely to produce useful data in a short time frame

3 It exposes a school yard to landslide risk

4 A geotechnical investigation is currently ongoing at this site

5 There is existing inclinometer casing at this site and the depth of sliding is relatively well known
The instrumentation (one IPI, one vwp and one pluviometer) was installed during February 2003 and the station was fully commissioned on $22^{\text {nd }}$ March 2003.

The continuous monitoring record shown in Figure 2 highlights a number of important features. The rainfall over the 2-year period is close to average and this is supported by the approx $1200 \mathrm{~mm}$ annual cumulative totals for both years. Still the period has produced three relatively minor rainfall events during May 2003, April and October 2004, which triggered some landslide movement at this site. The May 2003 event is discussed below. The pore water pressure curve also displays two important points. The vibrating wire piezometer was installed on the $3^{\text {rd }}$ February 2003 and did not indicate 'reasonable' pore water pressure until late June 2003, a period of 4 months after installation. However, since that time the pore water pressure data has shown considerable daily variation and superimposed on this variation a slow and steady rise in pressure. As this piezometer is installed at $3.9 \mathrm{~m}$ depth the variability displayed is considered to be partly related to atmospheric pressure variation.

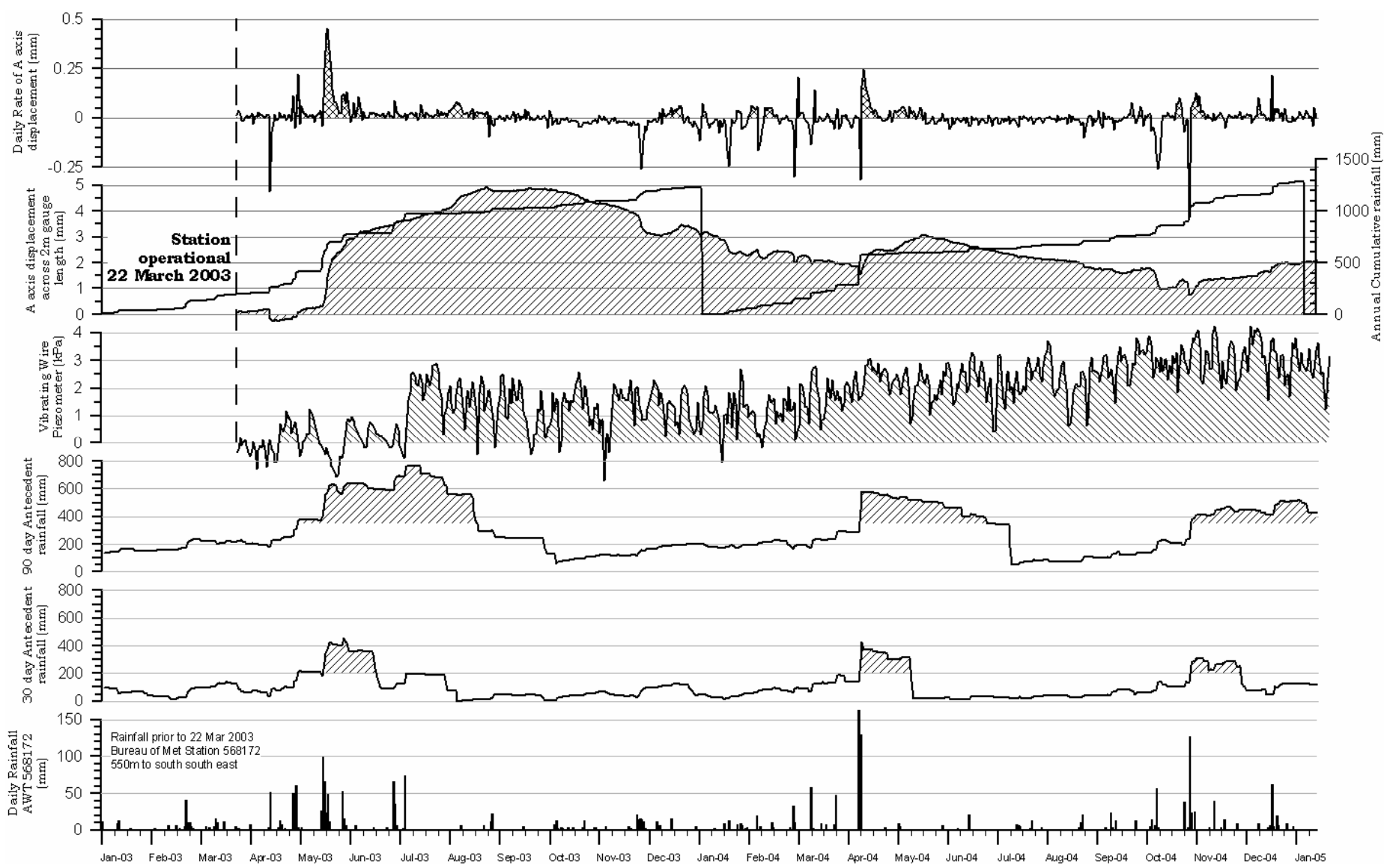

Figure 2. Continuous monitoring history, landslide Site $11322^{\text {nd }}$ March 2003 to 7 Jan 2005. Rainfall, pore water pressure, landslide cumulative displacement and rate of shear. 


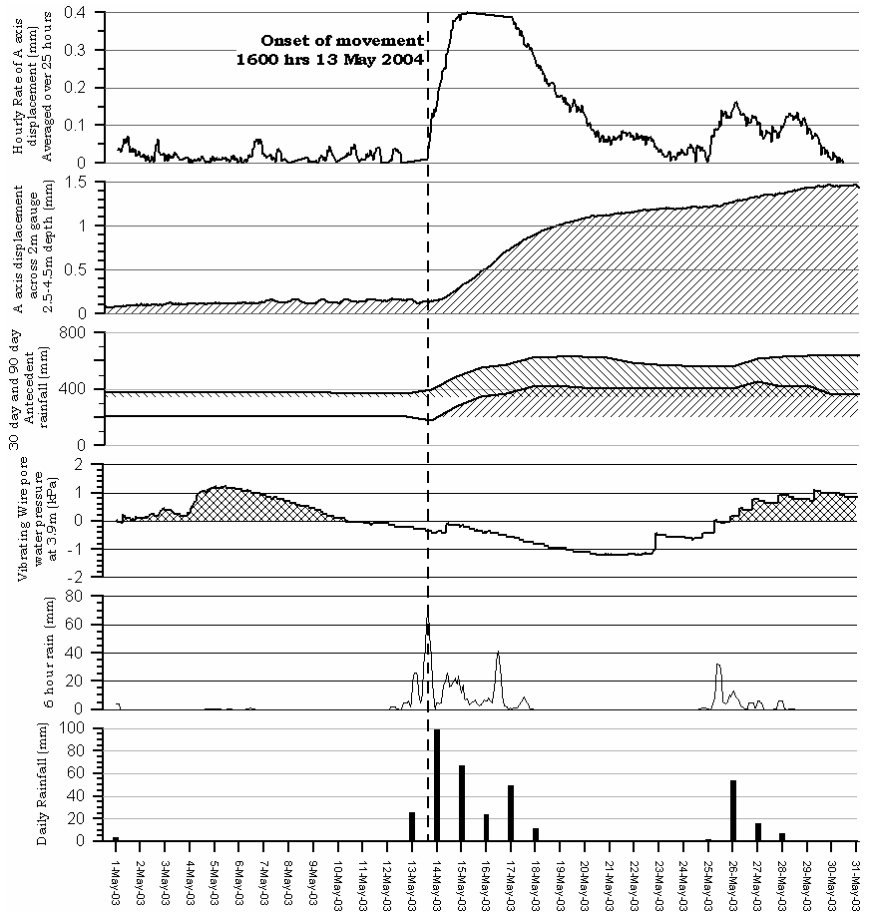

Figure 3. Continuous Monitoring record Site 113 for the May to August period 2003.

The hourly continuous monitoring record for May 2003 is shown in Figure 3 and this clearly shows that the landslide accelerated during the afternoon of the $13^{\text {th }}$ May, reached a peak velocity of $0.4 \mathrm{~mm} / 25$ hours on the $15^{\text {th }}$ May and slowed to $0.022 \mathrm{~mm} /$ day by the $25^{\text {th }}$ May 2003 . The landslide
$0.15 \mathrm{~mm} / 25$ hours in response to $53.4 \mathrm{~mm}$ of rain on the $26^{\text {th }}$ May and slowed essentially to zero on the $30^{\text {th }}$ May. However, as shown in Figure 2, the slide did continue moving episodically at extremely slow rates until late August 2003.

\section{DATA FROM REAL-TIME MONITORING STATION INSTALLED AT SITE 355}

Site 355 is a deep-seated slow moving 'slide' category landslide with a volume of approximately $35,000 \mathrm{~m}^{3}$. A comprehensive geotechnical investigation of this landslide, carried out by the University of Wollongong, has shown that this landslide presents a high risk of loss of life for adjacent residential dwellings, the proximity of which are clearly visible in Figure 4. This assessment was an important factor that resulted in the construction of this continuous monitoring station. Three IPI's, two vibrating wire piezometers and one rainfall pluviometer were installed at the site.

The continuous monitoring record of Site 355 is shown as Figure 5. Manual inclinometer profiles recorded from borehole GUOWsc02, as shown in Figures 4 and 6 , have recently confirmed that the depth of sliding in borehole 2 is between 4 and $5 \mathrm{~m}$ depth.

\section{then briefly accelerated again up to}

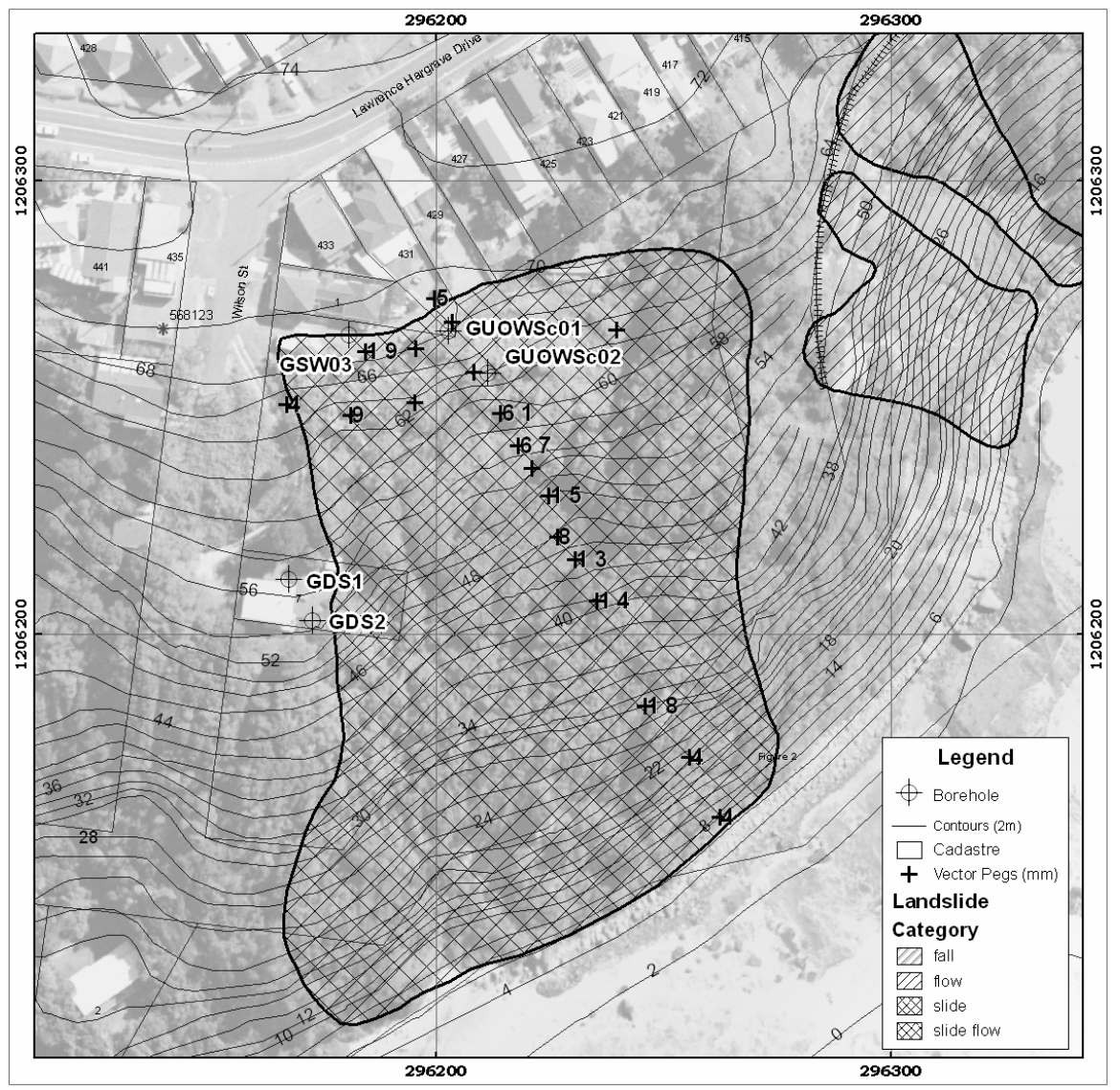

Figure 4. Site 355 landslide. Continuously recording field station is located at site of borehole GUOWSc02. Crosses indicate the array of vector pegs. 


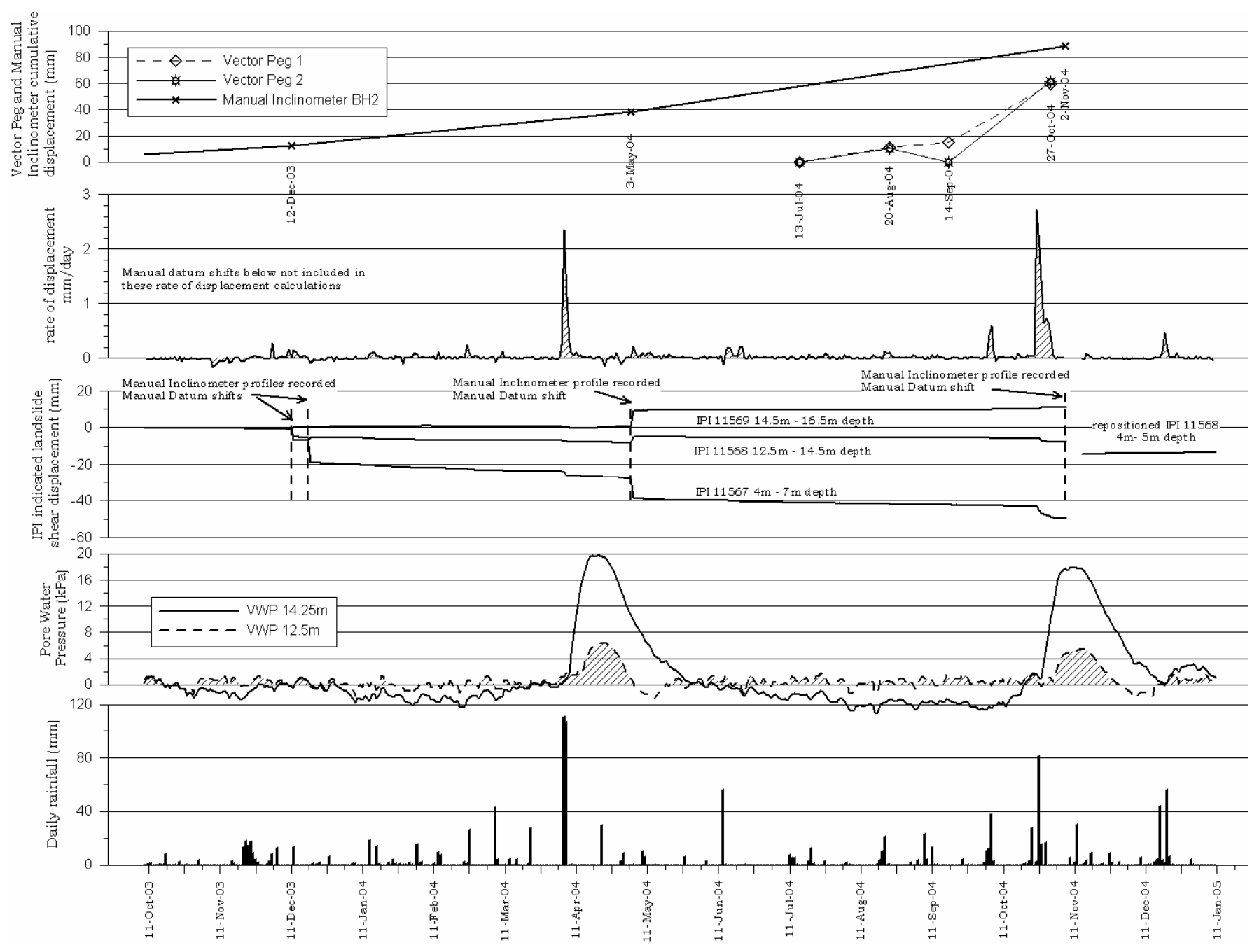

Figure 5. Continuous monitoring history, landslide Site 355 11th October 2003 to 2 Dec 2004. Rainfall, pore water pressure, landslide cumulative displacement, rate of shear, Vector Peg displacement and manual inclinometer displacement at $4 \mathrm{~m}$ depth

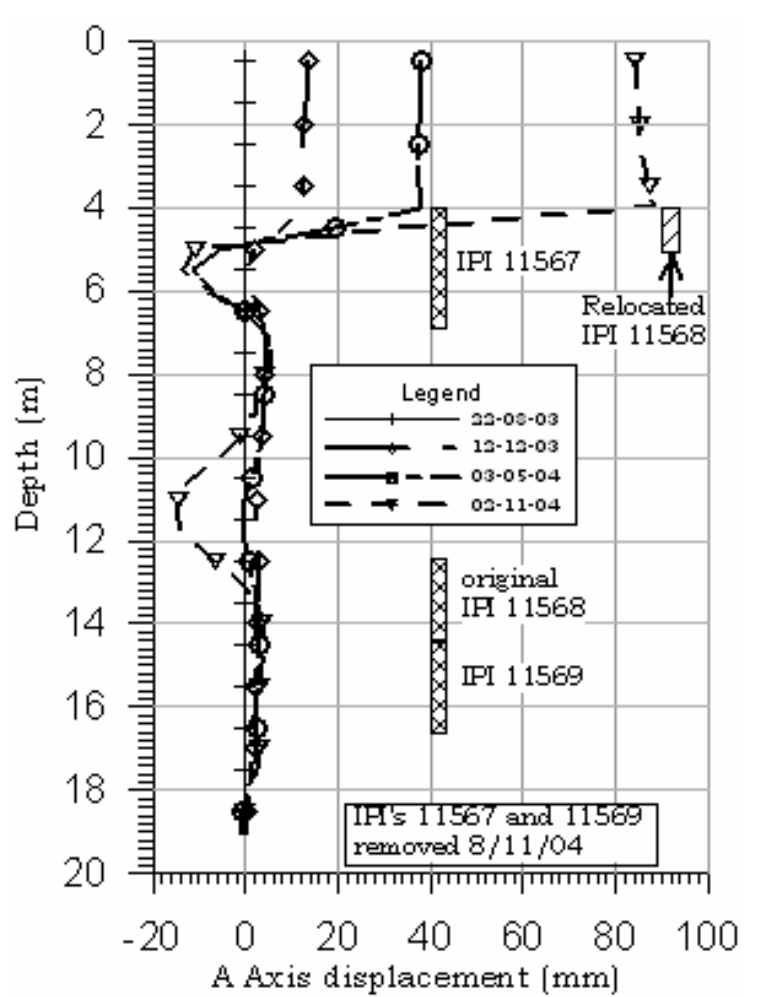

Figure 6. Manual inclinometer profiles, borehole GUOWSc02, Site 355.
Up until the $2^{\text {nd }}$ November 2004, the upper IPI 11567 at this site spanned the interval $4 \mathrm{~m}$ to $7 \mathrm{~m}$ that encompassed the base of the fill material and upper colluvium whilst the two deeper IPI's spanned the base of the colluvium and colluvium-bedrock interface.

The manual profiles also display two prominent upslope deflections in the casing over the $5 \mathrm{~m}$ to $6 \mathrm{~m}$ depth and $9 \mathrm{~m}$ to $13 \mathrm{~m}$ depth. The inclinometer was installed following difficult drilling operations and partially grouted and then backfilled with sand. Hence the upslope deflections are considered to be the result of poor annulus support. Hence any deflections indicated by IPI's 11568 and 11569 have been ignored.

This continuous dataset has highlighted several important issues. Firstly, the IPI's provide data regarding the relative displacement of two locations (per IPI instrument) in a borehole, as opposed to the full borehole profile obtained from running a manual inclinometer. Hence, the style (or profile) of landslide shear displacement experienced in a borehole should be known before an IPI can be strategically placed. 
Secondly, apparent negative displacement of IPI 11567 as shown in Figure 5, was a concern. However, a review of the manual profiles displayed in Figure 6 highlights the cause of the problem. IPI 11567 includes the IPI instrument itself, as mentioned above, a $0.45 \mathrm{~m}$ long instrument with the bottom wheels at the base of the $4 \mathrm{~m}$ to $7 \mathrm{~m}$ monitoring interval with a stainless steel tube $2.55 \mathrm{~m}$ long above that at the top of which is affixed the top wheels of the monitored depth at $4 \mathrm{~m}$. Figure 6 clearly shows that IPI 11567 was indeed being rotated uphill (indicated negative displacement) approximately $18 \mathrm{~mm}$ whilst the soft stainless steel tubing was flexing in the inclinometer casing and actually masking the real landslide shear displacement. This situation has been rectified after the latest manual profile was recorded by removing all three IPI's and simply reinstalling one IPI (IPI 11568 was arbitrarily selected) at the $4 \mathrm{~m}$ to $5 \mathrm{~m}$ depth interval. Preliminary data from this revised installation has already exhibited $2 \mathrm{~mm}$ downslope displacement. Interestingly, the Inclinometer casing has now exhibited a total displacement of approximately $90 \mathrm{~mm}$ over this $4 \mathrm{~m}$ to $5 \mathrm{~m}$ interval and the IPI was difficult to reinstall. Consequently we have already commissioned the installation of a new borehole in which we will tremmie grout in place the larger diameter $85 \mathrm{~mm}$ inclinometer casing. A new vibrating wire piezometer will also be installed to monitor pore water pressure at this shallow depth.

Notwithstanding these problems, the IPI's have provided excellent data. The IPI 11567 rate of shear displacement curve in Figure 3 clearly displays two prominent spikes of accelerated displacement commencing on the $4^{\text {th }}$ April and the $21^{\text {st }}$ October 2004. The movement event, which commenced on The 4th April, continued for 5 days and peaked at $2.4 \mathrm{~mm}$ per day. This was triggered by rainfall of $110 \mathrm{~mm}$ and $106 \mathrm{~mm}$ on consecutive days.

The movement event, which commenced on the 21st October 2004, lasted for 7 days and peaked at $2.7 \mathrm{~mm}$ per day (although this may have actually been almost 4 times higher at around $10 \mathrm{~mm}$ per day because of the problems discussed above) on the second day. A maximum daily rainfall of $81.5 \mathrm{~mm}$ and several other days of $15 \mathrm{~mm}$ to $30 \mathrm{~mm}$ triggered this short duration of movement.

The vibrating wire piezometers (vwp) have both shown quite strong responses to the rainfall. However, it is important to note that these two instruments were installed immediately above and below the bedrock colluvium interface, $7 \mathrm{~m}$ and $9 \mathrm{~m}$ below the current slide plane. As noted previously a new vwp will be installed at the depth of the slip surface in the near future.

\section{SITE 141 -INTRODUCTION}

Site 141 has been installed on a landslide that has previously disrupted three lanes of the six lane dual carriageway of the F6 Sydney to Wollongong Freeway (Figure 7). This field station is one of two that has been installed on this road in collaboration with the Southern Region of the Roads and Traffic Authority (RTA) of New South Wales during 2004. The second station is Site $153,1.5 \mathrm{~km}$ south of Site 141 and as no movement has occurred at this since the installation date, data from Site 153 is not being discussed in this paper.

The Site 141 landslide is approximately $200 \mathrm{~m}$ wide, $60 \mathrm{~m}$ long downslope and up to $22 \mathrm{~m}$ of colluvium has been encountered in boreholes drilled on the site. These dimensions indicate an approximate volume of $150,000 \mathrm{~m}^{3}$.

During 1988 a series of twenty $100 \mathrm{~mm}$ diameter vertical eductor wells were installed at this landslide site on the uphill side of the carriageway as shown in Figure 7 in an attempt to "de-water" and therefore, stabilize the landslide area. Each borehole was drilled to a depth of $25-30 \mathrm{~m}$ and at $10 \mathrm{~m}$ centers spanned a $200 \mathrm{~m}$ length of the road. Electrical pumps have been installed in each eductor well and the outlet of each is interconnected so that the daily volume of pumped water is logged.

Existing inclinometer records from this site spanning 15 years since the installation of the eductor wells however, show an average annual displacement at this site of approximately $10 \mathrm{~mm}$, with more movement in wet years and less in drier years.

The RTA is collaborating with the University and has funded the stations as part of a strategy to; (a) gain a better understanding of how both sites are

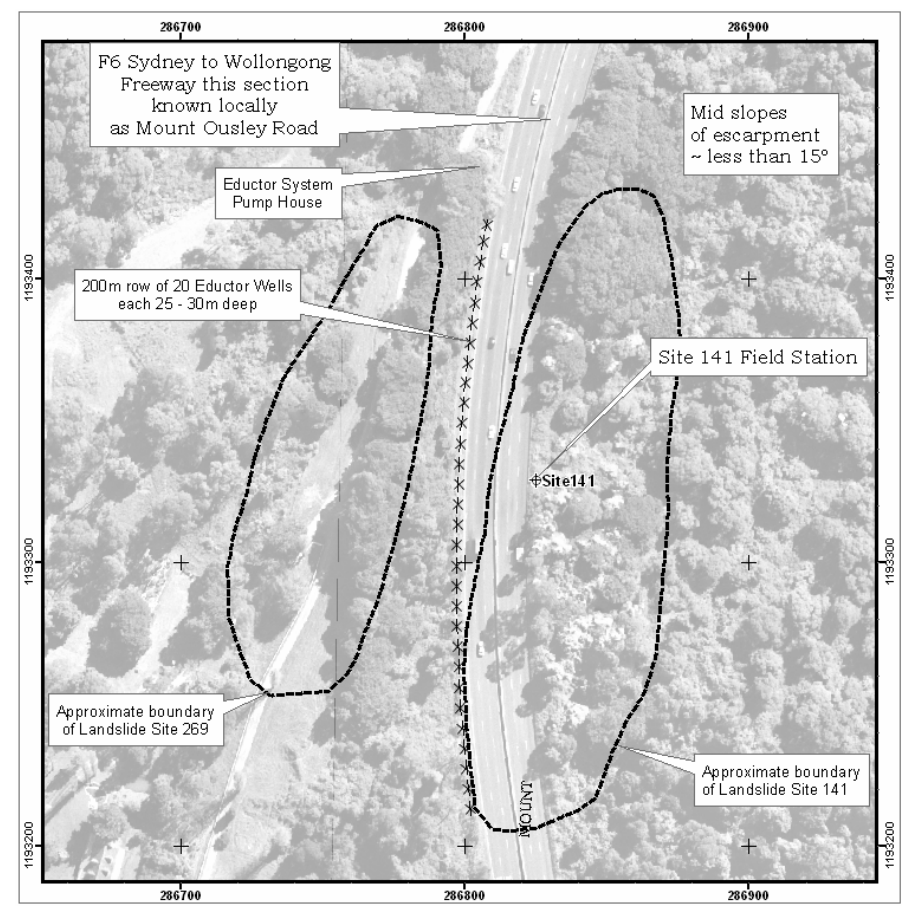

Figure 7. Site 141 on Mount Ousley Road (see Figure 1). 
performing, (b) examine means of reducing maintenance costs and (c) improve methods of managing risk to infrastructure and life.

\subsection{Data from real-time monitoring station installed at Site 141}

The two field stations on Mount Ousley Road were fully commissioned at 10:00am on Friday $30^{\text {th }}$ July 2004 and since that time negligible movement has been detected as shown in Figure 8. However, two rainfall events, $76.2 \mathrm{~mm}$ and $164.8 \mathrm{~mm}$ on the $2^{\text {nd }}$ and $22^{\text {nd }}$ October 2004 respectively have resulted in significant rises in pore water pressure at Site 141. Two vibrating wire piezometers have been installed at this site in the same borehole, one at $17.9 \mathrm{~m}$ depth within the colluvium material, and the second at $22.5 \mathrm{~m}$ depth within the bedrock material with existing manual inclinometer profiles showing shear displacement is occurring between these two depths.

The rise in pore water pressure on the $2^{\text {nd }}$ October and the subsequent 3 days was striking and some cause for concern. However, the rapid drop in pore pressure on the $5^{\text {th }}$ October was even more surprising. This process was repeated following the heavy rainfall of the $22^{\text {nd }}$ October although this time it was accompanied by curious pore water pressure fluctuations.

The field station does not log the eductor well flow rate at present (may in the future), rather this data is acquired at 6 monthly intervals via data exchange with another organisation. It is only upon viewing this data together with the pore water and rainfall data that a better understanding of the interrelationships develops. On the $12^{\text {th }}$ July 2004 , prior to the field station being commissioned, the eductor wells pumping flow rate had dropped below the preset threshold of 90 Kilolitres per day whereby the.pumps were turned off, being re-activated again on the $4^{\text {th }}$ October, following the rainfall on the $2^{\text {nd }}$ October.

At this early stage it is clear that pumping from the eductor wells inhibits the rise in pore water pressure at both vibrating wire instrument levels (i.e., both above and below the slide plane) and that the pore water pressure rises that do occur are dissipated rapidly. This of course has the positive effect of at least mitigating landslide movement at this site.

\section{DISCUSSION - PROPOSED ARRAY OF STATIONS DISTRIBUTED THROUGHOUT THE STUDY AREA}

There are four field stations operating in Wollongong at the present time and these represent the early stages of the University of Wollongong proposed network of real-time continuous monitoring stations. We propose to install up to 15 additional stations at some of the nearly 600 landslides documented within the area that pose a risk to residential areas or certain infrastructure components.

The need for such an array of stations has been well demonstrated during the August 1998 Wollongong rainfall event. During this event the city experienced $750 \mathrm{~mm}$ of rainfall during 5 days and the city was isolated from adjacent urban centres including Sydney for 24 hours. A total of 142 landslides were activated during and in the weeks following this event. However, during the emergency response phase, accurate information regarding rainfall was limited and information regarding landslide movement was not available, other than incoming reports of damage.

The proposed network of stations will facilitate the availability of accurate information in real-time

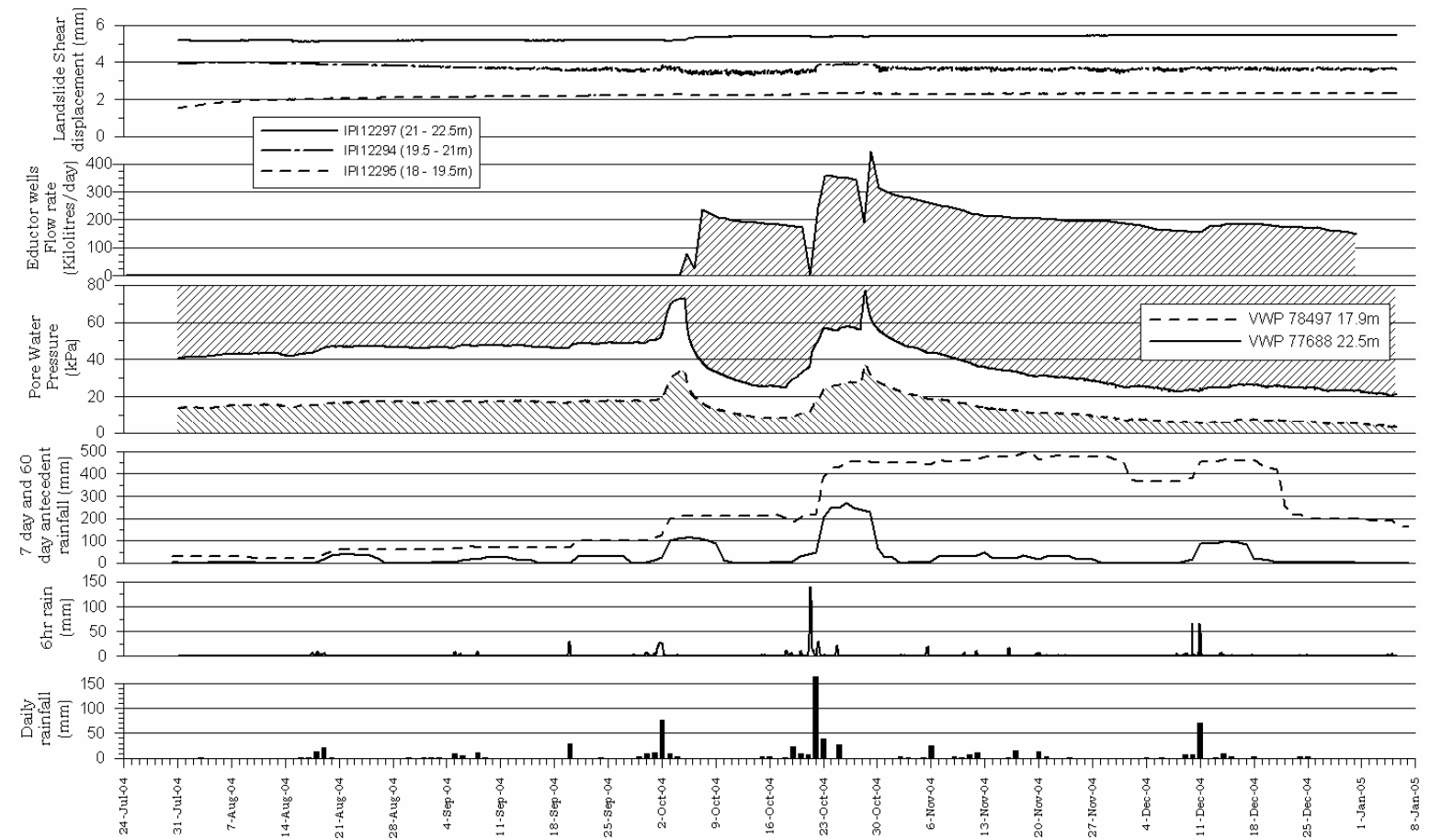

Figure 8. Continuous monitoring history, landslide Site 14130 th July to 7th Jan 2005. Daily and 6 hourly rainfall, pore water pressure, Eductor wells daily volumetric output, landslide cumulative displacement and rate of shear 
especially during emergency management situations and thereby enhance the rational allocation of limited resources during these peak demand situations.

The stations provide real-time information regarding the onset of landslide movement that is particularly important because of the episodic 'slip and stick' nature of many of the Wollongong landslides. This is well demonstrated by the performance of Site 355 during the recent late October 2004 rainfall event as discussed above. The landslide accelerated on the $21^{\text {st }}$ of October and the writers were aware at $9.00 \mathrm{am}$ on the morning of the $21^{\text {st }}$ that this was occurring. Local government authorities were informed immediately and inspections were carried out that morning. Over the next 7 days the event was monitored continuously and updated information was provided several times a day.

\section{WEB BASED MANAGEMENT OF CONTINUOUS REAL-TIME DATA}

Having fully automated the data collection process at the landslide sites and the transfer of that data to the office, the World Wide Web was considered to be the most appropriate way of managing the inbound data and its dissemination. This is especially important given the desired audience for the data being geotechnical colleagues, managers of essential infrastructure, managers of emergency services, police and their technical advisers and in some cases, other stakeholders.

Using the web to manage the data has important benefits. Firstly managing the data from the field stations has proven to take considerable time in the office using the commercial software described previously. Secondly, using the commercial software in the office does not in itself get the essential data out to the required audience.

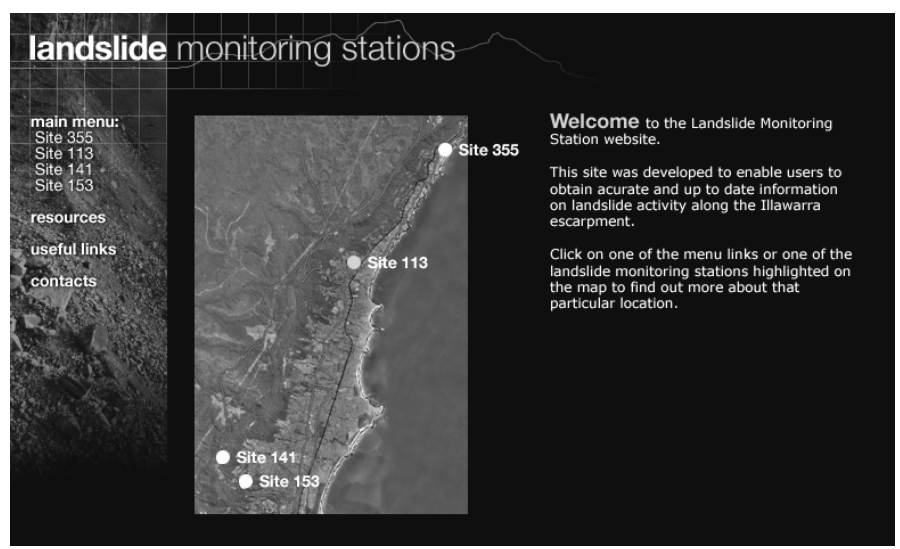

Figure 9. University of Wollongong Continuous Real-Time Landslide Monitoring Web page.

Using the ASP.NET framework with a database created in MS Access, the landslide research team in collaboration with the University of Wollongong Centre for Educational Development and Interactive
Resources (CEDIR) has developed web-based software to provide real-time graphical updates of the incoming data as it arrives from the field stations. The web-based facility is available via the University of Wollongong web portal http://landres.uow.edu.au/ which opens as shown in Figure 9. At present four sites are available and these can be selected from the menu on the left by clicking on the site locations on the index map.

The site specific pages open as shown in the upper part of Figure 10, in this case Site 355 has been selected. The most recent 2 weeks of data is always available at a glance by selecting the 2 week overview button. Furthermore, the database of existing landslide performance data is also available for review by selecting from a range of graphical outputs. The web-based hourly continuous monitoring record of In Place Inclinometers displacement at Site 355 for the 14 days up to $1^{\text {st }}$ November 2004 12.00am is also shown in Figure 10. This 2 week period includes the $21^{\text {st }}-23^{\text {rd }}$ October movement event at this site. Graphs of hourly data displaying IPI Total displacement, IPI rate, IPI azimuth, hourly rainfall and pore water pressure for any 14 day period can be simply generated. The 5 graph types are soon to be extended to 18 graph types and the display period is being extended up to 180 days with a fully interactive graphical user interface.

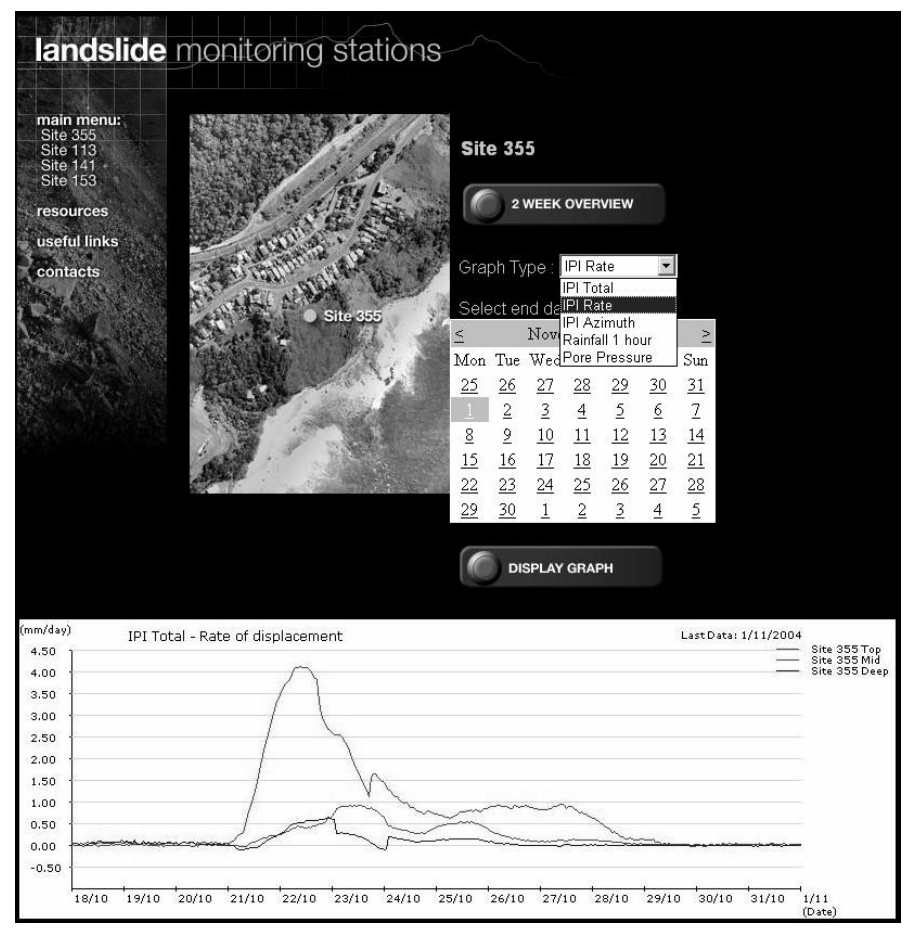

Figure 10. Site 355 Continuous Real-Time Monitoring web page with IPI Rate of Displacement Graph for the 2 weeks up to 12:00am hours on the $1^{\text {st }}$ November 2004

\section{FUTURE DEVELOPMENTS}

The web-based real-time facility is to be upgraded on several fronts during 2005. Firstly, due to the sensitive nature of the material presented the access 
will be password protected. At present the data supply from the field is based on a pre-programmed regional rainfall intensity. As experience with the landslide sites and instrumentation performance develops, the reporting of data could also be activated on the basis of specified magnitudes of (a) landslide displacement, or (b) rates of displacement, or (c) pore water pressure, or (d) refined site-specific rainfall thresholds.

The web-based software will, with the appropriate experience, also be configured to provide alerts based on rainfall, pore water pressure and or displacement thresholds. These alerts will be sent automatically to designated staff via a range of media including email and telephone (voice and text). Tabulated downloads of data will also be enabled.

The network of field monitoring stations is also proposed to be extended beyond Wollongong to other landslide areas within the state NSW and even interstate.

On a more general note the html address will also be expanded to access other areas of our landslide research at the Faculty of Engineering at the University of Wollongong.

\section{CONCLUSIONS}

Continuous real-time monitoring is an important component of quantitative landslide risk management especially during high magnitude (longer return period) rainfall events and emergency management operations. However, it is also important for risk assessment work in helping to quantitatively assess landslide frequency and hazard. In addition the data provides an important research component as the landslide performance data together with pore water pressure and rainfall contributes greatly to the understanding of landslide processes and triggering mechanisms. Such data recorded at 5 minute and 1 hour intervals is providing an unparalleled database of information.

Whilst Pedrozzi (2004) has recently suggested that the regional prediction of triggering of landslides is not possible using rainfall intensity/frequency methods in an area such as Canton Ticino in Switzerland, the writers strongly believe that a regional landslide triggering rainfall threshold (intensity/frequency) curve is relevant for the Illawarra area of New South Wales in Australia. In fact a preliminary threshold has already been proposed for this area (Flentje 1998, Flentje and Chowdhury 2001). It is understood that rainfall threshold curves for specific landslide sites will differ from a regional curve.

The continuous real-time monitoring discussed in this paper will lead to a refinement of the existing regional landslide triggering rainfall threshold (intensity/frequency) curve and the refinement and or development of specific threshold curves for the four sites. These are important developments as they will enhance our ability to provide early warning of landslide activity.

Coupled with these developments is the improved quantitative assessment of landslide frequency and hazard that this data will provide. With experience as the data record builds the rates of landslide displacement and frequency of events will be reviewed in comparison with structural damage and vulnerability tables.

\section{ACKNOWLEDGEMENTS}

The authors would like to acknowledge the support and help of Slope Indicator staff in Australia $\mathrm{Mr}$ Colin Viska and in Vancouver Mr. Alan Jones.

\section{REFERENCES}

Chowdhury, R, Flentje, P. and Hayne, M and Gordon, D., 2002. Strategies for Quantitative Landslide Hazard Assessment. Proceedings of the International Conference on Instability - Planning and Management. Conference, editors: RG McInnes and Jenny Jakeways, May 2002, Isle of Wight, UK, Thomas Telford, London, UK, pp 219-228.

Chowdhury, R. and Flentje, P., 2002b. Keynote Address Modern Approaches for Assessment and Management of Urban Landslides. Proceedings of the $3^{\text {rd }}$ International Conference on Landslides, Slope Stability and the Safety of Infrastructures. July $11-12$, Singapore. CI-Premier Conference Organisation, pp $23-36$.

Flentje, P. (1998). Computer Based Landslide Hazard and Risk Assessment. PhD Thesis, University of Wollongong, Australia.

Flentje, P. and Chowdhury, R. N, 2001. Aspects of Risk Management for Rainfall - Triggered Landsliding. Proceedings of the Engineering and Development in Hazardous Terrain Symposium, New Zealand Geotechnical Society Inc. University of Canterbury, Christchurch, New Zealand. The Institution of Professional Engineers New Zealand. August 24-25, pp 143-150.

Hendrickx, M., Wilson, R., Moon, A., Stewart I. \& Flentje, P. in prep. Slope hazard assessment on a coast road in New South Wales, Australia.

Ko Ko, C., 2001. Landslide Hazard and Risk Assessment Along a Railway Line, Ph.D. thesis, University of Wollongong, New South Wales, Australia

Ko Ko, C., Flentje, P and Chowdhury, R., 2004. Interpretation of Probability of landsliding triggered by rainfall. Landslides, Volume 1, Number 4, December, pp. 263 - 275. Springer.

Pedrozzi, G., 2004. Triggering of landslides in canton Ticino (Switzerland and prediction by the rainfall intensity and duration method. Bulletin of Engineering Geology and the Environment. Volume 63, Number 4, pp. $281-291$. 